\title{
Influence of Myocardial Fibrosis on Left Ventricular Hypertrophy in Patients with Symptomatic Severe Aortic Stenosis
}

\author{
Giorgio Golia $^{\mathrm{a}}$ Aldo D. Milano ${ }^{\mathrm{b}}$ Mikhail Dodonov $^{\mathrm{b}}$ Corinna Bergamini ${ }^{\mathrm{a}}$ \\ Giuseppe Faggian $^{b}$ Anna Tomezzolic Corrado Vassanelli ${ }^{a}$ \\ Dipartimento ad attività integrata Cardiovascolare e Toracico, ${ }^{\mathrm{a}}$ Unità operativa di Cardiologia, $\mathrm{e}^{\mathrm{b}}$ Unità \\ operativa di Cardiochirurgia, $\mathrm{e}^{\mathrm{C}}$ Dipartimento ad attività integrata di Patologia, Unità operativa di \\ Anatomia Patologica, Università di Verona, Verona, Italia
}

\section{Key Words}

Echocardiography $\cdot$ Aortic valve stenosis $\cdot$ Myocardial fibrosis $\cdot$ Ventricular function

\begin{abstract}
Aim: It was the aim of our study to determine whether myocardial fibrosis influences physiologic or non-physiologic left ventricular (LV) hypertrophy in severe aortic stenosis. Methods: Myocardial fibrosis was evaluated using specimens taken from the ventricular septum in 79 patients submitted to aortic valve replacement because of symptomatic aortic stenosis. Patients were considered to have physiologic LV hypertrophy if end-systolic wall stress, evaluated by echocardiography, was $<90 \mathrm{kdyn} / \mathrm{cm}^{2}$, while those with endsystolic wall stress $>90 \mathrm{kdyn} / \mathrm{cm}^{2}$ were considered to have non-physiologic hypertrophy. Results: Fibrosis tissue mass index was significantly inversely related with LV fractional shortening and directly related with LV diastolic and systolic diameter and LV mass index (LVMI). Patients with non-physiologic hypertrophy $(n=24)$ had a higher LVMI due to larger LV diastolic and systolic diameters with thinner wall, resulting in lower relative wall thickness. These patients had a higher fibrosis tissue mass index and impaired LV systolic and diastolic functions, as suggested by lower LV fractional
\end{abstract}

shortening and higher mean wedge pressure. At follow-up of 7.4 \pm 2.1 months, the LVMI and New York Heart Association class remained higher in patients with non-physiologic hypertrophy. Conclusions: Our study suggests a different quality of hypertrophies in patients with aortic stenosis, where myocardial fibrosis seems to be the critical abnormality that differentiates adaptive from maladaptive response to increased afterload.

Copyright $\odot 2011$ S. Karger AG, Basel

\section{Introduction}

Aortic valve stenosis (AS) is the most frequent expression of valvular heart diseases in the western population, and left ventricular hypertrophy (LVH) is a major compensatory mechanism in response to pressure overload $[1,2]$. The hypertrophy normalizes LV wall stress and maintains normal LV ejection [3]. However, recent studies questioned the beneficial role of LVH in AS, suggesting that increased LV mass is a predictor of LV dysfunction $[4,5]$. Impaired systolic and diastolic LV function was independently related to mortality after aortic valve replacement for aortic stenosis [6].

\section{KARGER}

Fax +41613061234 E-Mail karger@karger.ch www.karger.com
(C) 2011 S. Karger AG, Basel

$0008-6312 / 11 / 1203-0139 \$ 38.00 / 0$

Accessible online at:

www.karger.com/crd
Giorgio Golia, MD

Dipartimento ad attività integrata Cardiovascolare e Toracico

Unità operativa di Cardiologia

P.le Stefani, 1, IT-37126 Verona (Italy)

Tel. +39 045807 2320, E-Mail giorgio.golia@ ospedaleuniverona.it 
This deleterious effect of the hypertrophy is due to the presence of myocyte degeneration and myocardial fibrosis in the hypertrophic ventricle. Myocardial fibrosis seems to be the major determinant of both diastolic and systolic functions in aortic stenosis: myocardial fibrosis increases, LV end-diastolic pressure increases and ejection fraction decreases [7]. The increment in LV mass secondary to the increase in afterload might not be able to normalize wall stress and maintain LV function in the presence of myocardial fibrosis $[8,9]$.

Our aim was to determine whether the presence of myocardial fibrosis influences physiologic or non-physiologic hypertrophic response in severe aortic stenosis.

\section{Methods}

\section{Study Group}

From January 1998 to December 2005, 896 patients underwent aortic valve replacement at the University Hospital of Verona. Among them, 81 patients with high-quality echocardiographic examination performing M-mode and Echo-Doppler quantitative analyses, without previous myocardial infarction, critical coronary artery disease, prior cardiac surgery or aortic insufficiency grade $>1$ were enrolled by a single surgeon (G.F.) to carry out a biopsy of the interventricular septum.

The following types of prostheses were placed using a previously described procedure [10]: Hancock biological valve in 46 patients (57\%), Sorin Bicarbon mechanical valve in 13 patients (16\%), Carbomedics mechanical valve in 10 patients (12\%) and Edwards Perimount pericardial valve in 12 patients (15\%). The sizes of the implanted prostheses were as follows: $21 \mathrm{~mm}$ in 18 (22\%), $23 \mathrm{~mm}$ in 46 (57\%), $25 \mathrm{~mm}$ in 15 (19\%) and $27 \mathrm{~mm}$ in $2 \mathrm{pa}-$ tients (3\%).

Patients were divided into two groups according to end-systolic wall stress (calculated as described below): patients with end-systolic wall stress $\leq 90 \mathrm{kdyn} / \mathrm{cm}^{2}$ were considered to have physiologic hypertrophy, while those with end-systolic wall stress $>90 \mathrm{kdyn} /$ $\mathrm{cm}^{2}$ were considered to have non-physiologic hypertrophy [8].

A clinical and echocardiographic follow-up was obtained in each patient at 7.4 \pm 2.1 months (range 3.5-11.4) after surgery.

\section{Echocardiography}

All patients underwent an M-mode, bidimensional and Doppler echocardiographic study before surgery. All echocardiographic measurements were performed according to the American Society of Echocardiography [11]. LV end-diastolic diameter (LVEDD), LV end-systolic diameter (LVESD), LV diastolic and systolic septal and inferior wall thickness (LVPWTd and LVPWTs) were measured by M-mode echocardiography. LV fractional shortening (LVFS) was calculated as: $100 \cdot$ (LVEDD LVESD)/LVEDD. LV mass was calculated according to the Devereux formula [12] and indexed by body surface area (LV mass index, LVMI). Relative wall thickness (RWT) was calculated according to the following formula: RWT $=(2 \cdot \mathrm{LVPWTd}) / \mathrm{LV}$ internal diastolic diameter. LV end-systolic wall stress (ESWS) was calculated as: ESWS $=0.334 \cdot \mathrm{P} \cdot \mathrm{LVESD} /[\mathrm{LVPWT} \cdot(1+$
LVPWTs/LVESD)], where P is the LV peak systolic pressure calculated as the sum of the systolic blood pressure taken by sphygmomanometry plus peak aortic gradient evaluated by Doppler [13]. The degree of AS was assessed by estimation of Doppler peak gradient, Doppler mean gradient and aortic valve area, calculated using the standard formula of continuity equation.

Heart Catheterization

All patients underwent selective coronary angiography. Fiftyseven patients (37 with physiologic hypertrophy, 20 with nonphysiologic hypertrophy) underwent right heart catheterization with measurements of right ventricular and pulmonary artery pressure and mean pulmonary wedge pressure.

\section{Morphological Study}

Specimens were taken from the ventricular septum in a manner similar to surgical subaortic myectomy. The biopsy material was preserved in $10 \%$ formaldehyde solution overnight and then totally embedded in paraffin. It was cut into 2 - $\mu \mathrm{m}$-thick sections which were stained with haematoxylin-eosin and Masson's trichrome. The amount of myocardial fibrous tissue was determined by point counting using a $10 \times 10$ grid at a total magnification of $\times 100[14,15]$. A fibrosis index (FI) was calculated by dividing the sum of the fibrotic areas of the section by that of the total tissue area and was expressed as percentage, as described by Tanaka et al. [16]. According to the FI, the patients were classified as having no or mild fibrosis $(<20 \%)$, moderate fibrosis $(21-50 \%)$ or severe fibrosis $(>50 \%)$. Fibrous tissue mass index (FTMI) was expressed as $\mathrm{FI} \times \mathrm{LVMI} / 100$.

\section{Statistical Analysis}

Data are expressed as mean \pm 1 standard deviation. Differences between continuous variables among groups were analysed by the two-tailed unpaired $t$ test. Event frequency among the groups of patients was analysed by the $\chi^{2}$ test. Linear regression analysis was used to evaluate the relations between variables. A $\mathrm{p}$ value $<0.05$ was considered statistically significant. StatView release 5.0 software (SAS Institute Inc., copyright 1992-1998) was used for statistical analysis.

\section{Results}

\section{Patients}

There were 2 in-hospital deaths (2\%) due to low cardiac output syndrome, and these patients were excluded from the study. In the early postoperative period, there was 1 cerebrovascular event, 14 low cardiac output syndromes and 3 acute renal failures that required haemodialysis for a few days.

Table 1 summarizes demographic, echocardiographic, haemodynamic and morphologic parameters in the whole study population. The mean age was $71.2 \pm 9.9$ years; 47 patients (59.5\%) were $>70$ years of age and 37 (46.8\%) were men. The mean New York Heart Association (NYHA) functional status was $2.5 \pm 0.7: 8$ patients 
Table 1. Demographic, echocardiographic, haemodynamic and morphologic parameters of the study population

\begin{tabular}{|c|c|c|c|c|}
\hline & $\begin{array}{l}\text { All patients } \\
(\mathrm{n}=79)\end{array}$ & $\begin{array}{l}\text { Physiologic hyper- } \\
\text { trophy }(\mathrm{n}=55)\end{array}$ & $\begin{array}{l}\text { Non-physiologic } \\
\text { hypertrophy }(\mathrm{n}=24)\end{array}$ & $\mathrm{p}$ \\
\hline Age, years & $71.2 \pm 9.9$ & $70.5 \pm 10.2$ & $72.7 \pm 9.1$ & 0.32 \\
\hline Males/females & $37 / 42$ & $10 / 14$ & $27 / 28$ & n.s. \\
\hline Diabetes & 14 & 11 & 3 & n.s. \\
\hline Hypertension & 22 & 14 & 8 & n.s. \\
\hline NYHA class & $2.5 \pm 0.7$ & $2.4 \pm 0.7$ & $2.8 \pm 0.7$ & 0.016 \\
\hline LVEDD, mm & $49.1 \pm 5.4$ & $46.9 \pm 4.6$ & $54.3 \pm 3.0$ & $<0.0001$ \\
\hline LVESD, mm & $31.4 \pm 6.0$ & $28.8 \pm 5.0$ & $37.5 \pm 3.0$ & $<0.0001$ \\
\hline LVPWTd, mm & $13.2 \pm 1.6$ & $13.5 \pm 1.4$ & $12.5 \pm 1.8$ & 0.015 \\
\hline LVPWTs, mm & $18.3 \pm 2.2$ & $18.9 \pm 2.0$ & $16.8 \pm 1.8$ & $<0.0001$ \\
\hline LVSWTd, mm & $14.8 \pm 1.6$ & $15.1 \pm 1.5$ & $14.0 \pm 1.5$ & 0.004 \\
\hline LVSWTs, mm & $19.2 \pm 2.1$ & $19.7 \pm 2.0$ & $18.2 \pm 1.9$ & 0.004 \\
\hline LVFS, $\%$ & $36.4 \pm 7.5$ & $38.9 \pm 7.0$ & $30.9 \pm 5.5$ & $<0.0001$ \\
\hline RWT & $0.55 \pm 0.10$ & $0.58 \pm 0.08$ & $0.46 \pm 0.08$ & $<0.0001$ \\
\hline LVMI, g/m² & $193 \pm 38$ & $183 \pm 33$ & $215 \pm 39$ & 0.0005 \\
\hline ESWS, $\mathrm{kdyn} / \mathrm{cm}^{2}$ & $75.9 \pm 25.0$ & $62.3 \pm 14.6$ & $107.2 \pm 11.2$ & $<0.0001$ \\
\hline Aortic PG, mm Hg & $80 \pm 17$ & $82 \pm 17$ & $73 \pm 16$ & 0.025 \\
\hline Aortic MG, mm Hg & $51 \pm 12$ & $53 \pm 13$ & $46 \pm 10$ & 0.016 \\
\hline Aortic VA, $\mathrm{cm}^{2} / \mathrm{m}^{2}$ & $0.39 \pm 0.09$ & $0.37 \pm 0.08$ & $0.44 \pm 0.10$ & 0.0012 \\
\hline RVSP, $\mathrm{mm} \mathrm{Hg}(\mathrm{n}=57)$ & $37.7 \pm 10.8$ & $34.4 \pm 6.8$ & $43.9 \pm 14.5$ & 0.0011 \\
\hline RVDP, $\mathrm{mm} \mathrm{Hg}(\mathrm{n}=57)$ & $2.19 \pm 2.45$ & $1.5 \pm 2.0$ & $3.6 \pm 2.7$ & 0.0015 \\
\hline PASP, $\operatorname{mm~Hg}(\mathrm{n}=57)$ & $36.0 \pm 11.7$ & $32.6 \pm 11.8$ & $43.0 \pm 19.6$ & 0.0007 \\
\hline PADP, $\mathrm{mm} \mathrm{Hg}(\mathrm{n}=57)$ & $14.3 \pm 6.5$ & $11.8 \pm 3.7$ & $19.6 \pm 7.8$ & $<0.0001$ \\
\hline MWP, mm Hg $(\mathrm{n}=57)$ & $14.3 \pm 7.5$ & $12.3 \pm 5.1$ & $19.8 \pm 9.4$ & 0.0002 \\
\hline FI, \% & $30.5 \pm 14.7$ & $26.6 \pm 11.5$ & $39.6 \pm 17.3$ & 0.0002 \\
\hline FTMI, $\mathrm{g} / \mathrm{m}^{2}$ & $62.5 \pm 38.8$ & $51.1 \pm 28.7$ & $88.7 \pm 46.3$ & $<0.0001$ \\
\hline
\end{tabular}

n.s. = Not significant; LVSWTd = LV diastolic septal wall thickness; LVSWTs= LV systolic septal wall thickness; aortic PG = aortic peak gradient; aortic MG = aortic mean gradient; aortic VA = index aortic valve area; $\mathrm{RVSP}=$ right ventricular systolic pressure; $\mathrm{RVDP}=$ right ventricular diastolic pressure; PASP = pulmonary artery systolic pressure; PADP = pulmonary artery diastolic pressure; $\mathrm{MWP}=$ mean wedge pressure.

(10.1\%) were in class I, 27 (34.1\%) in class II, 41 (51.8\%) in class III, and $3(3.7 \%)$ in class IV.

The mean FTMI was $62.5 \pm 37.9 \mathrm{~g} / \mathrm{m}^{2}$. Twenty-two patients $(27.8 \%)$ had mild myocardial fibrosis, with a mean FTMI of $17.4 \pm 5.1 \mathrm{~g} / \mathrm{m}^{2} ; 45$ patients $(57.0 \%)$ had moderate myocardial fibrosis, with a mean FTMI of 56.6 $\pm 12.7 \mathrm{~g} / \mathrm{m}^{2} ; 12$ patients (15.1\%) had severe myocardial fibrosis, with a mean FTMI of $103.5 \pm 28.5 \mathrm{~g} / \mathrm{m}^{2}$.

\section{Cardiac Function, Hypertrophy and Morphology}

In the whole study population, LVFS was inversely related to ESWS, LVMI and FTMI (fig. 1). ESWS and LV remodelling, expressed by LVMI, end-diastolic volume and end-systolic volume, were significantly related to FTMI (fig. 2).

Fifty-five patients had physiologic hypertrophy, while 24 patients had non-physiologic hypertrophy. The char- acteristics of the patients with physiologic and non-physiologic hypertrophy are reported in table 1 . No differences were found in the mean age, sex, history of hypertension or diabetes. Patients with non-physiologic LVH showed a higher NYHA functional class $(2.8 \pm 0.7$ vs. 2.4 $\pm 0.7 ; \mathrm{p}=0.016)$, a lower peak (73 \pm 16 vs. $82 \pm 17 \mathrm{~mm}$ $\mathrm{Hg} ; \mathrm{p}=0.025)$ and mean $(46 \pm 10$ vs. $53 \pm 13 \mathrm{~mm} \mathrm{Hg}$; $\mathrm{p}=0.01)$ aortic gradient and a higher aortic valve area $\left(0.44 \pm 0.10\right.$ vs. $\left.0.37 \pm 0.08 \mathrm{~cm}^{2} / \mathrm{m}^{2} ; \mathrm{p}=0.0012\right)$.

Patients with non-physiologic hypertrophy had a higher LVMI (215 \pm 39 vs. $\left.183 \pm 33 \mathrm{~g} / \mathrm{m}^{2} ; \mathrm{p}=0.0005\right)$. However, this higher LV mass was due to larger LV diameters (LVEDD $54.3 \pm 3.0$ vs. $46.9 \pm 4.6 \mathrm{~mm}$; p $<0.0001$ ) with thinner wall (LVPWTd $12.5 \pm 1.8$ vs. $13.5 \pm 1.4$ $\mathrm{mm} ; \mathrm{p}=0.015)$, resulting in lower RWT $(0.46 \pm 008 \mathrm{vs}$. $0.58 \pm 0.08 ; \mathrm{p}<0.0001)$. These patients had more important fibrosis (FTMI $88.3 \pm 45.8$ vs. $51.1 \pm 28.7 \mathrm{~g} / \mathrm{m}^{2}$; 

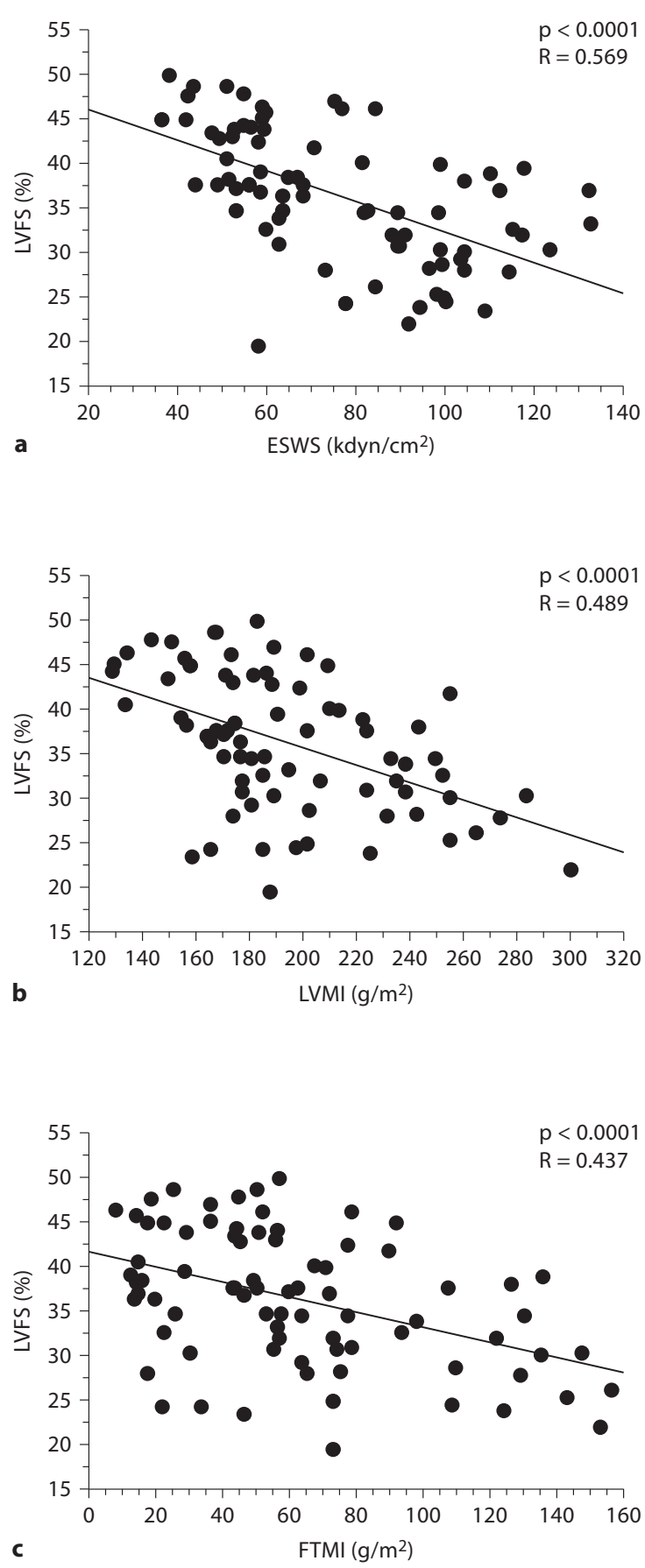

Fig. 1. Relationship between LVFS and ESWS (a), LVMI (b) and FTMI (c) in the study patients. $\mathrm{p}<0.0001)$ and impaired LV systolic and diastolic functions, as suggested by lower LVFS (30.9 \pm 5.5 vs. $38.9 \pm$ $7.0 \% ; \mathrm{p}<0.0001)$ and higher mean wedge pressure $(19.8$ \pm 9.4 vs. $12.3 \pm 5.1 \mathrm{~mm} \mathrm{Hg} ; \mathrm{p}=0.0002$ ) (fig. 3 ).

\section{Follow-Up}

At $7.4 \pm 2.1$ months of follow-up, NYHA class decreased both in patients with physiologic $(1.75 \pm 0.65)$ and non-physiologic hypertrophy $(2.38 \pm 0.82)$. However, the reduction was larger in the first group, so that the NYHA class was lower in patients with physiologic hypertrophy at follow-up (fig. 4a). NYHA class was significantly related to fibrosis, with a significant reduction at follow-up in patients with grade 1 and 2 FTMI, and not in those with grade 3 (fig. $4 \mathrm{~b}$ ).

LV wall thickness decreased in both groups, whereas LV diameters remained constant (except for a small increment in LVEDD in patients with physiologic hypertrophy). RWT decreased in patients with physiologic hypertrophy, so that there was no difference between the two groups at follow-up. LVMI decreased both in patients with physiologic and in those with non-physiologic hypertrophy, but remained significantly higher in the second group. LVFS did not change (table 2).

\section{Discussion}

Our study shows that the hypertrophic response to pressure overload in aortic stenosis is related to myocardial fibrosis. In the presence of myocardial fibrosis, the increment of LV mass is inadequate to normalize wall stress and to maintain normal LV function. Both myocardial fibrosis and non-physiologic hypertrophy are negatively related to NYHA class improvement after surgery.

For a long time, LVH in aortic stenosis has been considered an adaptive process to normalize increased wall stress and to maintain LV function [1-3, 17]. Several studies reported an inverse relationship between LV systolic wall stress and LV systolic function in patients with aortic stenosis [18-20]. However, hypertrophy is not always an adaptive process $[4,5]$, because it is the consequence of a complex neuroendocrine pressure-induced process that may produce both beneficial adaptive and adverse maladaptive hypertrophy [21]. In our study, although there was a high correlation between LV systolic wall stress and LVFS, the LV mass was inversely related to LV function. The main reason why hypertrophy may represent a deleterious mechanism of compensation to elevated afterload is apoptosis and myocardial fibrosis $[8,15]$. 


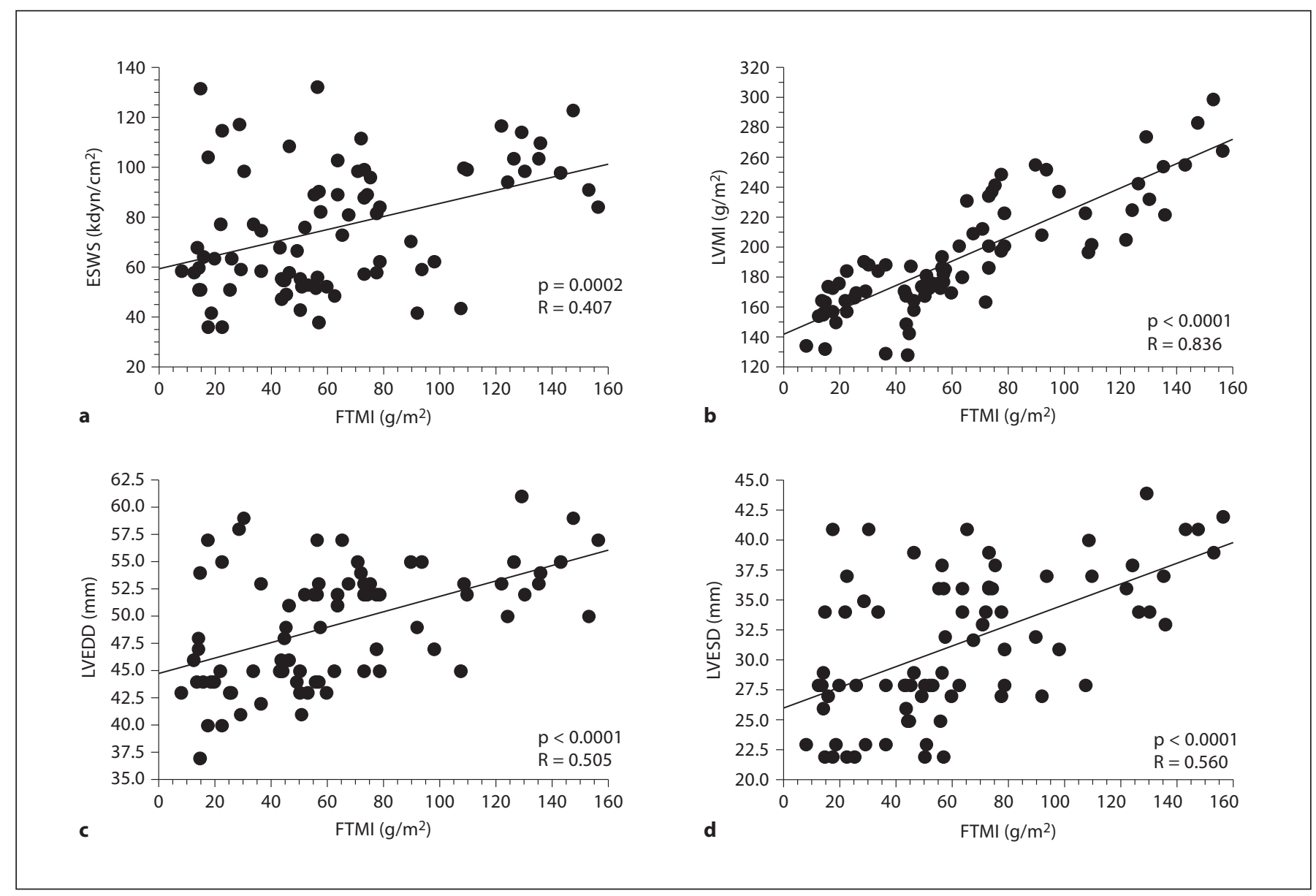

Fig. 2. Relationship between FTMI and ESWS (a), LVMI (b), LVEDD (c) and LVESD (d) in the study patients.

In our study, myocardial fibrosis was inversely related to LVFS and directly related to ESWS and LV remodelling, expressed by LVMI, end-diastolic volume and end-systolic volume. The better relationship between FTMI and LVM suggests that development of fibrosis is the main morphological alteration [7] responsible for the larger increment in LV mass and LV dysfunction found in the group of patients with non-physiologic hypertrophy. These results are in line with those of Polyakova et al. [22] who found a strong relation between progressive extracellular matrix fibrosis and LV systolic function in patients with AS.

Myocardial fibrosis was larger in the group of patients with non-physiologic hypertrophy compared to patients with hypertrophy, adequate to normalize wall stress. In patients with physiologic hypertrophy, the increment in $\mathrm{LV}$ mass was related to the increment in wall thickness rather than to the increase in LV diameters (concentric hypertrophy): this increment in thickness normalizes wall stress and maintains LVFS. On the contrary, in patients with elevated stress, the larger increment in LV mass was secondary to a minor increase in LV thickness and a larger increase in LV diameters (eccentric hypertrophy).

At follow-up, although a reduction in wall thickness was observed in both groups, LVMI remained higher, and ventricular systolic function (evaluated as LVFS) did not recover in patients with non-physiologic hypertrophy.

It is possible that non-physiologic hypertrophy in the presence of a great LV mass may be the expression of more severe and prolonged LV systolic overload, with an increase in wall thickness without an increase in volume in the earlier phase, producing impairment of diastolic filling and increased LV filling pressures and resulting in an increment in LV volume in the later phase [21]. In our study, this may be suggested by the higher mean pulmonary capillary wedge pressure and right ventricular pressure, the expression of LV diastolic dysfunction, in pa- 


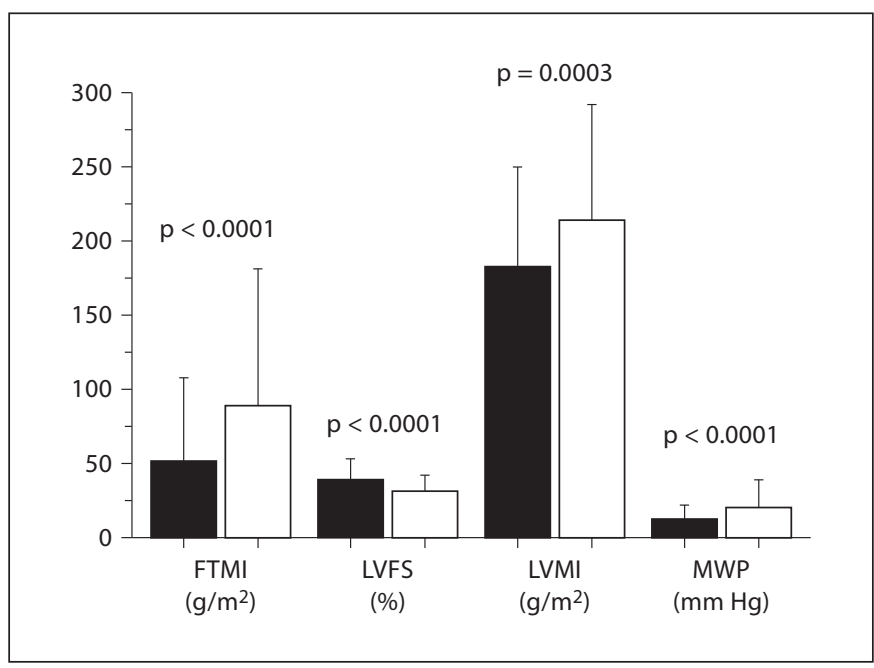

Fig. 3. Mean \pm 2 SD of FTMI, LVFS, LVMI and mean wedge pressure (MWP) in patients with physiologic (black bar) and nonphysiologic hypertrophy (white bar).

Table 2. NYHA class and echocardiographic parameters at follow-up

\begin{tabular}{lccc}
\hline & $\begin{array}{l}\text { Physiologic } \\
\text { hypertrophy }\end{array}$ & $\begin{array}{l}\text { Non-physiologic } \\
\text { hypertrophy }\end{array}$ & $\mathrm{p}$ \\
\hline NYHA class & $1.7 \pm 0.6^{* *}$ & $2.4 \pm 0.8^{*}$ & 0.0005 \\
LVEDD, mm & $47.6 \pm 4.8^{*}$ & $52.7 \pm 2.8$ & $<0.0001$ \\
LVESD, mm & $28.8 \pm 5.7$ & $36.3 \pm 2.8$ & $<0.0001$ \\
LVPWTd, mm & $10.9 \pm 1.7^{* *}$ & $11.5 \pm 1.8^{*}$ & n.s. \\
LVSWTd, mm & $12.1 \pm 1.7^{* *}$ & $12.7 \pm 2.2^{* *}$ & n.s. \\
LVFS, \% & $39.5 \pm 9.2$ & $30.9 \pm 5.2$ & $<0.0001$ \\
RWT & $0.46 \pm 0.11^{* *}$ & $0.44 \pm 0.80$ & n.s. \\
LVMI, g/m & $136 \pm 35^{* *}$ & $180 \pm 48^{* *}$ & $<0.0001$ \\
\hline
\end{tabular}

n.s. = Not significant; LVSWTd $=$ LV diastolic septal wall thickness. ${ }^{*} \mathrm{p}<0.01,{ }^{* *} \mathrm{p}=0.0001$ versus baseline.

tients with non-physiologic hypertrophy. However, although it was not possible to evaluate the duration of aortic stenosis in our patients, the age of patients with physiologic and non-physiologic hypertrophy did not differ, which was also reported by Serneri et al. [8]. Furthermore, in patients with non-physiologic hypertrophy, the peak and the mean aortic gradients were lower and the aortic valve area was larger compared to patients with physiologic hypertrophy.

Alternatively, early activation of maladaptive growth signals and enzymes involved in collagen synthesis and

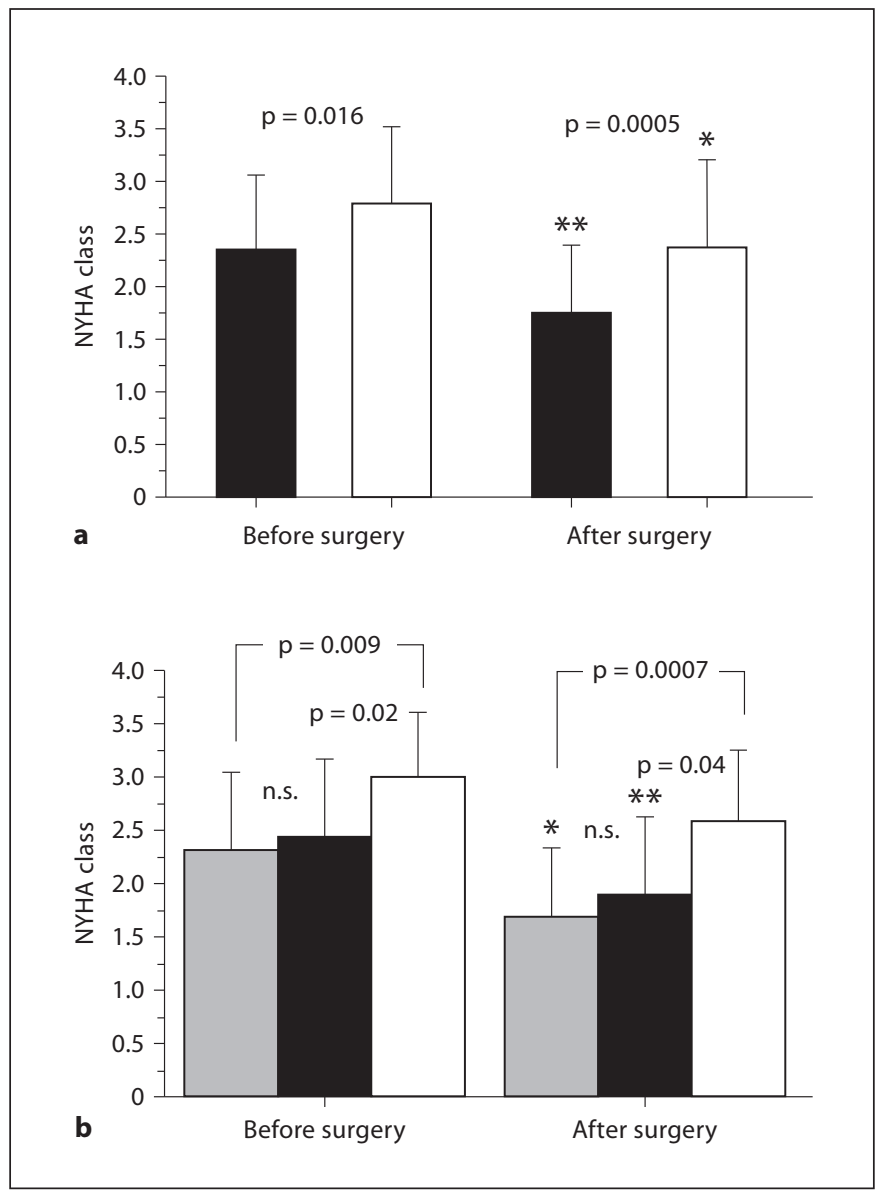

Fig. 4. a NYHA class before and after surgery in patients with physiologic (black bar) and non-physiologic hypertrophy (white bar) $\left({ }^{*} \mathrm{p}<0.0001,{ }^{* *} \mathrm{p}=0.009\right.$ vs. baseline). b NYHA class before and after surgery according to the grade of fibrosis $\left({ }^{*} \mathrm{p}=0.001\right.$, ** $\mathrm{p}<0.0011$ vs. baseline). Grey bar = Grade 1 FTMI; black bar = grade 2 FTMI; white bar = grade 3 FTMI. ANOVA: $\mathrm{p}=0.03$ before the operation, $\mathrm{p}=0.002$ after the operation.

degradation leading to deleterious remodelling could occur $[8,23]$. Serneri et al. [8] have recently reported that in patients with aortic stenosis the presence of adequate hypertrophy is related to the capacity of myocytes to generate growth factors, such as insulin-like growth factor 1 and endothelin 1, able to increase contractility and wall thickness. On the contrary, non-physiologic hypertrophy might be related to the incapacity to produce these factors and to the generation of angiotensin II. In the study by Heymans et al. [23], transcript levels of both tissue inhibitors of metalloproteinases 1 and 2 were significantly related to the degree of fibrosis in AS patients. Thus, hypertrophic growth of the heart is the result of a complex combinatorial action of various stimuli, which may have 
different effects on gene expression and protein synthesis in different patients [24].

Some limitations of our study should be considered. First, although our study shows a relationship between myocardial fibrosis, hypertrophy and LV function, it does not demonstrate that fibrosis is the cause of LV dysfunction. However, previous studies have reported myocardial fibrosis as an anatomopathologic substrate to LV dysfunction. Secondly, we have enrolled only a small number of patients submitted to aortic valve surgery, op- erated by one surgeon of our Division. Thirdly, all our patients were symptomatic; therefore, our results may not be attributed to asymptomatic patients with severe aortic stenosis.

In conclusion, our study suggests the presence of a different quality of hypertrophy in patients with aortic stenosis, in which myocardial fibrosis seems to be the critical abnormality to differentiate adaptive and maladaptive response to increased afterload.

\section{References}

1 Bonow RO, Carabello BA, Chatterjee K, de Leon ACJ, Faxon DP, Freed MD, et al: 2008 focused update incorporated into the ACC/ AHA 2006 guidelines for the management of patients with valvular heart disease: a report of the American College of Cardiology/ American Heart Association Task Force on Practice Guidelines (Writing Committee to revise the 1998 guidelines for the management of patients with valvular heart disease). Endorsed by the Society of Cardiovascular Anesthesiologists, Society for Cardiovascular Angiography and Interventions, and Society of Thoracic Surgeons. J Am Coll Cardiol 2008;52:e1-e142.

2 Carabello BA, Paulus WJ: Aortic stenosis. Lancet 2009;373:956-966.

>3 Grossman W, Jones D, McLaurin LP: Wall stress and patterns of hypertrophy in the human left ventricle. J Clin Invest 1975;56:5664.

4 Chambers J: The left ventricle in aortic stenosis: evidence for the use of ACE inhibitors. Heart 2006;92:420-423.

5 Kupari M, Turto H, Lommi J: Left ventricular hypertrophy in aortic valve stenosis: preventive or promotive of systolic dysfunction and heart failure? Eur Heart J 2005;26:17901796.

6 Lund O, Flo C, Jensen FT, Emmertsen K Nielsen TT, Rasmussent BS, Hansen OK, Pilegaard HK, Kristensen LH: Left ventricular systolic and diastolic function in aortic stenosis. Prognostic value after valve replacement and underlying mechanisms. Eur Heart J 1997;18:1977-1987.

7 Hein S, Arnon E, Kostin S, Schonburg M, Elsasser A, Polyakova V, et al: Progression from compensated hypertrophy to failure in the pressure-overloaded human heart: structural deterioration and compensatory mechanisms. Circulation 2003;107:984-991.

-8 Serneri GG, Modesti PA, Boddi M, Cecioni I, Paniccia R, Coppo M, et al: Cardiac growth factors in human hypertrophy. Relations with myocardial contractility and wall stress. Circ Res 1999;85:57-67.
9 Weidemann F, Herrmann S, Stork S, Niemann M, Frantz S, Lange V, et al: Impact of myocardial fibrosis in patients with symptomatic severe aortic stenosis. Circulation 2009;120:577-584.

10 Milano AD, De Carlo M, Mecozzi G, D’Alfonso A, Scioti G, Nardi C, et al: Clinical outcome in patients with 19-mm and 21-mm St Jude aortic prostheses: comparison at long-term follow-up. Ann Thorac Surg 2002; 73:37-43.

11 Lang RM, Bierig M, Devereux RB, Flachskampf FA, Foster E, Pellikka PA, Picard MH, Roman MJ, Seward J, Shanewise JS, Solomon SD, Spencer KT, St John Sutton M, Stewart WJ: Recommendations for chamber quantification: a report from the American Society of Echocardiography's Guidelines and Standards Committee and the Chamber Quantification Writing Group, developed in conjunction with the European Association of Echocardiography, a branch of the European Society of Cardiology. J Am Soc Echocardiogr 2005; 18:1440-1463.

12 Devereux RB, Reichek N: Echocardiographic determination of left ventricular mass in man. Anatomic validation of the method. Circulation 1977;55:613-618.

13 Legget ME: Usefulness of parameters of left ventricular wall stress and systolic function in the evaluation of patients with aortic stenosis. Echocardiography 1999;16:701-710.

14 Baandrup U, Olsen EG: Critical analysis of endomyocardial biopsies from patients suspected of having cardiomyopathy. 1. Morphological and morphometric aspects. $\mathrm{Br}$ Heart J 1981;45:475-486.

15 Lund O, Kristensen LH, Baandrup U, Hansen OK, Nielsen TT, Emmertsen K, et al: Myocardial structure as a determinant of pre- and postoperative ventricular function and long-term prognosis after valve replacement for aortic stenosis. Eur Heart J 1998;19: 1099-1108.
16 Tanaka M, Fujiwara H, Onodera T, Wu DJ, Hamashima Y, Kawai C: Quantitative analysis of myocardial fibrosis in normals, hypertensive hearts, and hypertrophic cardiomyopathy. Br Heart J 1986;55:575-581.

17 Lorell BH, Carabello BA: Left ventricular hypertrophy: pathogenesis, detection, and prognosis. Circulation 2000;102:470-479.

18 Carabello BA, Green LH, Grossman W, Cohn LH, Koster JK, Collins JJ Jr: Hemodynamic determinants of prognosis of aortic valve replacement in critical aortic stenosis and advanced congestive heart failure. Circulation 1980;62:42-48

19 Carabello BA, Williams H, Gash AK, Kent R, Belber D, Maurer A, et al: Hemodynamic predictors of outcome in patients undergoing valve replacement. Circulation 1986; 74: 1309-1316.

20 Gunther S, Grossman W: Determinants of ventricular function in pressure-overload hypertrophy in man. Circulation 1979;59: 679-688.

-21 Opie LH, Commerford PJ, Gersh BJ, Pfeffer MA: Controversies in ventricular remodelling. Lancet 2006;367:356-367.

22 Polyakova V, Hein S, Kostin S, Tibor Z, Schaper J: Matrix metalloproteinases and their tissue inhibitors in pressure-overloaded human myocardium during heart failure progression. J Am Coll Cardiol 2004;44: 1609-1618

23 Heymans S, MD, Schroen B, Vermeersch P, Milting H, Gao F, Kassner A, Gillijns H, Herijgers $\mathrm{P}$, Flameng W, Carmeliet $\mathrm{P}$, Van de Werf F, Pinto YM, Janssens S: Increased cardiac expression of tissue inhibitor of metalloproteinase- 1 and tissue inhibitor of metalloproteinase- 2 is related to cardiac fibrosis and dysfunction in the chronic pressureoverloaded human heart. Circulation 2005; 112:1136-1144

24 Hefti MA, Harder BA, Eppenberger HM Schaub MC: Signaling pathways in cardiac myocyte hypertrophy. J Mol Cell Cardiol 1997;29:2873-2892. 